\title{
Separation of 1,1'-bi-2-naphthol enantiomers by continuous chromatography in simulated moving bed
}

\author{
Luís S. Pais, José M. Loureiro and Alírio E. Rodrigues* \\ Laboratory of Separation and Reaction Engineering, Faculty of Engineering, University of \\ Porto, Rua dos Bragas, 4099 Porto Codex, Portugal
}

(Received 29 January 1996; accepted 18 July 1996)

\begin{abstract}
The chromatographic separation of 1,1'-bi-2-naphthol enantiomers with 3,5-dinitrobenzoyl phenylglycine bonded to silica gel stationary phases is studied. Continuous chromatography in simulated moving bed (SMB) is analyzed by modeling, simulation and operation of a SMB pilot unit Licosep 12-26 from Separex (France).

A model for the prediction of the cyclic steady-state performance of the SMB is developed based on the analogy with the true moving bed (TMB). The model assumes axial dispersion flow for the liquid phase, linear driving force (LDF) approximation for intraparticle mass transfer rate and takes into account multicomponent adsorption equilibria.

The SMB package allows the simulation of the pilot unit. The effect of operating variables (switching time, extract and feed flow rates, section length) and number of mass transfer units on the SMB performance is analyzed. The SMB performance is characterized by purity, recovery, solvent consumption and adsorbent productivity. The package also allows the simulation of the dynamic evolution of internal profiles for the transient operation of a TMB. The operation of the SMB pilot unit was carried out for the separation of racemic mixtures of bi-naphthol enantiomers. Using a 8-column configuration purities as high as $94.5 \%$ of the more retained species in the extract and $98.9 \%$ of the less retained species in the raffinate were obtained. Copyright 1996 Elsevier Science Ltd
\end{abstract}

Keywords: Simulated moving bed; continuous chromatography; separation of enantiomers.

\section{INTRODUCTION}

Adsorptive separations are becoming increasingly important in chemical engineering (Knaebel, 1995). The simulated moving bed (SMB) technology developed by UOP (Broughton, 1961) has been used in chemical industry for several separations known as SORBEX processes (de Rosset et al., 1981; Johnson, 1989; Johnson and Kabza, 1993). They include the Parex process for the recovery of $p$-xylene from a mixture of $\mathrm{C}_{8}$ aromatics, the Molex process for the extraction of $n$-paraffins from branched and cyclic hydrocarbons, the Olex process to separate olefins from paraffins and the Sarex process for the recovery of fructose from fructose/glucose mixtures in the production of high fructose corn syrup HFCS (Broughton, 1968, 1984; Broughton et al., 1970; de Rosset et al., 1980, 1981). More than a hundred SMB units are operated worldwide (Humphrey, 1995). The heart of the SMB technology is a rotary valve which periodically changes

*Corresponding author. E-mail: arodrig@fe.up.pt. Tel.: 351-2-2041671. Fax: 351-2-2041674. the position of feed, eluent, extract and raffinate lines along the bed. In this way, the solid movement in a true moving bed (TMB) is simulated.

Continuous chromatography in SMB also eliminates drawbacks of batch chromatography, namely dilution of species and low adsorbent utilization (Bailly et al., 1984; Hotier and Ballanec, 1991; Balannec and Hotier, 1993; Bailly and Nicoud. 1993; Gottschall et al., 1994).

The separation of xylenes from the aromatic fraction $C_{8}$ has been studied both in vapor and liquid phase by adsorption on zeolites using the four-section SMB configuration (Storti et al., 1988, 1989a) and the $C_{8}$ and $C_{5}$ separation in a six-port $S M B$ pilot plant operating in the vapor phase (Storti et al.. 1992; Baciocchi et al, 1995).

The SMB technology has been recently applied in the areas of biotechnology, pharmaceuticals and fine chemistry. Pilot and industrial SMB for such applications have been developed by UOP (Gattuso et al., 1994, 1995) and SEPAREX (Nicoud, 1992).

The most important application in the field of food industry is the fructose/glucose separation using ionexchange resins. This separation has been studied in 
a three-section and four-section SMB configuration (Ching and Ruthven, 1985; Ching et al., 1985). The same process has been reported by Hashimoto et al. (1983) and Nicoud (1992).

Other applications include the separation of carbohydrate mixtures such as fructose/dextran, raffinose/ dextran and fructose/raffinose (Barker et al., 1990; Ching et al., 1992), glucose/xylose/arabinose (Balannec and Hotier, 1993), glucose/sorbitol (Kubota et al., 1989), and palatinose/trehalulose (Kishihara et al., 1989). Ching et al. (1988) have also studied experimentally the monoethanolamine/methanol separation on a ion-exchange resin. Another application of the SMB technology reported by Hashimoto et al. $(1987,1989)$ is the desalination of saccharides and amino acids using adsorbent resins and distilled water as solvent.

More recent applications are related with chiral technology. The separation of enantiomers is an important issue in various areas and particularly in the health-related field. It is well known that isomers can have different therapeutical value and there is pressure of regulatory agencies for the separation of isomers (Sheldon, 1993). The separation of enantiomers by conventional techniques is difficult because separation factors are low and therefore SMB technology is appropriate provided chromatographic phases for enantiomer separation are available (Nicoud, 1993; Stinton, 1995). It should be pointed out that scaling down of the Sorbex flowsheet becomes less economical than using a system of individual beds segmented by valves, and feed and product lines (Keller, 1995).

Examples of enantiomers separations have been reported: 1-phenyl-ethanol (Negawa and Shoji, 1992), praziquantel (Ching et al., 1993), 3-chloro-1-phenylpropanol (Dandekar et al., 1995), D,L-threonine (Fuchs et al., 1992) and 1a,2,7,7a-tetrahydro-3-methoxynaphtha-(2,3b)-oxirane (Sandoz epoxide) enantiomers in cellulose triacetate columns using methanol as eluent (Nicoud et al., 1992, 1993; Rodrigues et al., 1995a, b).

The objective of this paper is to study the separation of enantiomers of 1,1'-bi-2-naphthol (Fig. 1) in 3,5-dinitrobenzoyl phenylglycine bonded to silica gel columns using heptane/isopropanol $(72 / 28)$ as eluent by using SMB chromatography.

The work involves the following steps:

(i) development of a model for the SMB and numerical solution of model equations;

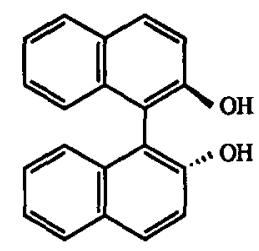

Fig. 1. 1,1'-bi-2-naphthol. (ii) understanding SMB process by using the simulation package to predict the effect of operating variables on the SMB performance;

(iii) operation of the SMB pilot unit for the binaphthol system and comparison with simulated results.

\section{MODELING OF A SIMULATED MOVING BED}

Models available in literature for SMB separation processes have been summarized by Ruthven and Ching (1989). There are two main strategies of modeling SMB processes: one represents the real SMB and the other the equivalent TMB. Models can also be classified according to the description of fluid flow in continuous-flow models (plug flow or axial dispersion flow) and mixing cell models (Hidajat et al., 1986a, b; Ching et al., 1987, 1988).

Some authors considered mass transfer rate inside particles described by the linear driving force approximation (Hashimoto et al., 1983; Ching and Ruthven, 1985; Storti et al., 1988, 1989b; Rahman et al., 1994; Hassan et al., 1995; Chu and Hashim, 1995). However, others used the equilibrium theory and neglected mass transfer resistances and axial mixing (Storti et al., 1989a, 1993; Mazzotti et al., 1994).

\section{Simulated Moving-Bed (SMB) and True Moving-Bed} $(T M B)$ strategies of modeling

The simulated moving bed can be represented by two different models: the real SMB and the true moving bed, TMB. In the SMB sketched in Fig. 2, the countercurrent flow of the solid is simulated by moving the eluent, extract, feed and raffinate lines one column forward in the fluid flow direction at fixed time intervals. In the Sorbex technology this is achieved with a rotary valve as mentioned in the Introduction section; in the Licosep 12-26 there are 12 individual beds with valves in each column and corresponding lines for the various streams. The

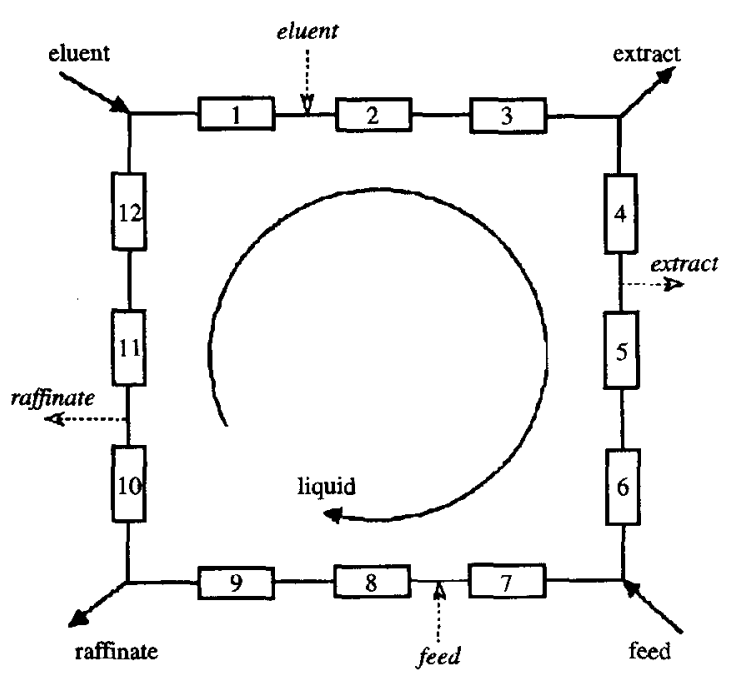

Fig. 2. Schematic diagram of the four-section SMB. 


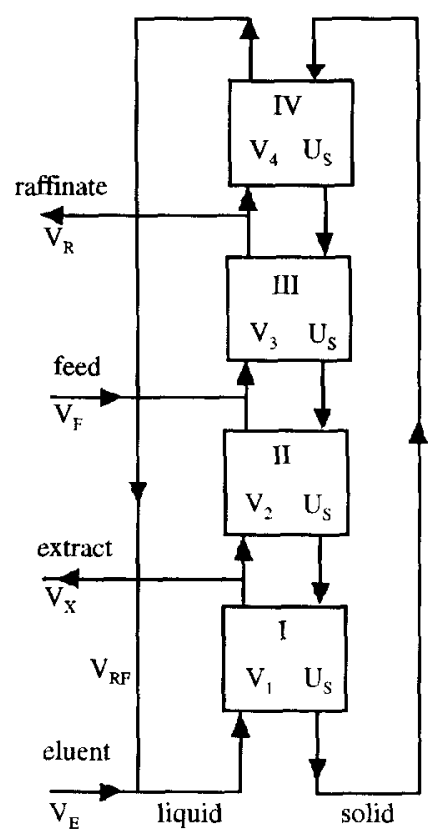

Fig. 3. Schematic diagram of the four-section TMB.

Licosep technology is a result of joint efforts of IFP (French Institute of Petroleum) and Separex (Hotier and Ballanec, 1991); the technology is now available through NOVASEP. SA (Vandoeuvre-lès-Nancy, France).

In the true moving bed (TMB) shown in Fig. 3 the liquid and the solid phases flow in opposite directions. The liquid flowing out of zone IV is recycled to zone I while the solid coming out of zone I is recycled to zone IV.

In both approaches. zone I is located between eluent and extract nodes, zone II is between extract and feed nodes, zone III separates feed and raffinate nodes and finally zone IV is between raffinate and eluent nodes. Also, the less-retained species A is recovered in the raffinate stream and the more retained species $B$ is collected in the extract stream.

Both SMB and TMB systems have similar cyclic steady-state performances; therefore, one can simulate and obtain the optimum operating conditions for the SMB, using the TMB model since it requires lower computing time. In fact, the cyclic behavior of the simulated moving bed can be calculated from the steady-state model of the true moving bed, taking into account the relation between the solid velocity $u_{s}$ and the rotation period for switching timel $\Delta T$ in SMB operation, i.e.

$$
u_{\mathrm{s}}=L_{\mathrm{c}} / \Delta T
$$

where $L_{c}$ is the column length.

The equivalence between the SMB and its corresponding TMB is made by keeping constant the liquid velocity relative to the solid velocity:

$$
v_{j}^{\mathrm{SMB}}=v_{j}^{\mathrm{TMB}}+u_{s}
$$

where $v_{j}$ is the interstitial fluid velocity in the $j$ section of the moving bed.

The design problem of a TMB (or its equivalent SMB) consists on setting the flow rates in each section allowing the desired separation. Some constraints have to be met if one wants to recover the less-adsorbed component $\mathrm{A}$ in the raffinate and the more-retained component $\mathrm{B}$ in the extract. These constraints are expressed in terms of net fluxes of components in each section. In zone 1 the heavier species B must move upwards, in zone II the light species must move upwards, in zone III the net flux of $B$ must be downwards and in zone IV the net flux of A has to be downwards, i.e.

$\frac{Q_{1} c_{B}}{\dot{M} q_{B}}>1 . \quad \frac{Q_{\mathrm{II}} c_{\mathrm{A}}}{\dot{M}_{q_{\mathrm{A}}}}>1 . \quad \frac{Q_{\mathrm{III} c_{B}}}{\bar{M}_{q_{H}}}<1, \quad \frac{Q_{\mathrm{IV}} c_{\mathrm{A}}}{\bar{M}_{q_{\mathrm{A}}}}<1$

where $\mathrm{Q}_{\mathrm{I}}, Q_{\mathrm{II}}, Q_{\mathrm{III}}, Q_{\mathrm{IV}}$ are the volumetric liquid flow rates in the various sections of the TMB, $\dot{M}$ is the solid flow rate, $C_{A}, C_{B}$ are the concentrations of species $\mathrm{A}$ and $\mathrm{B}$ in the liquid phase and $q_{\mathrm{A}}, q_{\mathrm{B}}$ are the adsorbed concentrations of components $\mathrm{A}$ and $\mathrm{B}$. respectively.

\section{Model development}

The package developed for the transient TMB system considers axial dispersion flow for the bulk fluid phase, linear driving force (LDF) for the intraparticle mass transfer rate and takes into account multicomponent adsorption equilibria. The model equations are

Mass balance in a volume element of the bed:

$$
\begin{aligned}
& \varepsilon D_{t, j} \frac{\hat{r}^{2} c_{i j}}{r z^{2}}-z v_{j} \frac{\hat{c} c_{i j}}{i z}+(1-\varepsilon) u_{x} \frac{\hat{i} q_{i j}}{i z} \\
& =i \frac{i(i j}{i t}+(1-c) \frac{i q_{i j}}{i t}
\end{aligned}
$$

where $i(i=\mathrm{A}, \mathrm{B})$ refers to the species in the mixture and $j(j=1,2,3,4)$ is the section number, $c_{i j}$ and $q_{i j}$ are the fluid-phase and average-adsorbed-phase concentrations of species $i$ in section $j$ of the TMB, respectively, $z$ is the axial coordinate, $t$ is the time variable, $s$ is the bed porosity, $u_{\mathrm{s}}$ is the solid velocity, $v_{j}$ is the fluid velocity and $D_{l, j}$ is the axial dispersion coefficient in section $j$.

Mass balance in the adsorbent particles:

$$
u_{s} \frac{i q_{i j}}{i=}+k\left(q_{i j}^{*}-q_{i j}\right)=\frac{i q_{i j}}{i t}
$$

where $k$ is the intraparticle mass transfer coefficien 1 and $q_{i j}^{*}$ is the adsorbed-phase concentration in equilibrium with $c_{i j}$.

Boundary conditions:

$$
\begin{gathered}
z=0, \quad \dot{c}_{i j}-\frac{D_{L j}}{v_{j}} \frac{d c_{i j}}{d z}=c_{i j .0} \\
z=L_{j,} \quad \frac{\mathrm{d} c_{i j}}{\mathrm{~d} z}=0 \quad \text { and } \quad q_{i j}=q_{i j+1.0}
\end{gathered}
$$


Multicomponent adsorption equilibrium isotherm:

$$
\begin{aligned}
& q_{A j}^{*}=f_{A}\left(c_{A j}, c_{B j}\right) \\
& q_{B j}^{*}=f_{B}\left(c_{A j}, c_{B j}\right) .
\end{aligned}
$$

Any type of multicomponent isotherm can be dealt with, the most common being the Langmuir-type equation $q_{i j}^{*}=q_{m} b_{i} c_{i j} /\left(1+\sum b_{i} c_{i j}\right)$.

Mass balances at the nodes of the inlet and outlet lines of the TMB

$$
\begin{gathered}
\text { Eluent node: } c_{i 1,0}=\frac{v_{4}}{v_{1}} c_{i 4, L_{j}} \\
\text { Extract node: } c_{i 2,0}=c_{i 1, L_{j}} \\
\text { Feed node: } c_{i 3,0}=\frac{v_{2}}{v_{3}} c_{i 2, L_{j}}+\frac{v_{F}}{v_{3}} c_{i}^{F} \\
\text { Raffinate node: } c_{i 4,0}=c_{i 3, L_{j}}
\end{gathered}
$$

with the relations between fluid velocities in the four zones of TMB:

$v_{4}=v_{R F}, \quad v_{1}=v_{4}+v_{E}, \quad v_{2}=v_{1}-v_{X}, \quad v_{3}=v_{2}+v_{F}$.

Introducing the dimensionless variables $x=z / L_{j}$ and $\theta=t / \tau_{s}$ with $\tau_{s}=L_{j} / u_{s}=N_{s} \Delta T$ (where $N_{s}$ is the number of columns per section) the model equations become

$$
\begin{gathered}
\frac{1}{P e_{j}} \frac{\partial^{2} c_{i j}}{\partial x^{2}}-\frac{\partial c_{i j}}{\partial x}+\frac{(1-\varepsilon)}{\varepsilon} \frac{1}{\gamma_{j}} \frac{\partial q_{i j}}{\partial x} \\
=\frac{1}{\gamma_{j}} \frac{\partial c_{i j}}{\partial \theta}+\frac{(1-\varepsilon)}{\varepsilon} \frac{1}{\gamma_{j}} \frac{\partial q_{i j}}{\partial \theta} \\
\frac{\partial q_{i j}}{\partial x}+\alpha_{j}\left(q_{i j}^{*}-q_{i j}\right)=\frac{\partial q_{i j}}{\partial \theta} .
\end{gathered}
$$

Boundary conditions:

$$
\begin{gathered}
x=0, \quad c_{i j}-\frac{1}{P e_{j}} \frac{\mathrm{d} c_{i j}}{\mathrm{~d} x}=c_{i j, 0} \\
x=1, \quad \frac{\mathrm{d} c_{i j}}{\mathrm{~d} x}=0 \text { and } q_{i j}=q_{i j+1,0} .
\end{gathered}
$$

\section{Model parameters}

The model parameters are:

$\frac{(1-\varepsilon)}{\varepsilon}$ (ratio between solid and fluid volumes)

$\gamma_{j}=\frac{v_{j}}{u_{s}} \quad$ (ratio between fluid and solid velocities)
$P e_{j}=\frac{v_{j} L_{j}}{D_{L_{j}}} \quad$ (Peclet number) $\alpha_{j}=\frac{k L_{j}}{u_{s}}=k \tau_{s} \quad \begin{gathered}\text { (number of intraparticle mass trans- } \\ \text { fer units). }\end{gathered}$

Adsorption equilibrium parameters have to be added to the list above.

\section{Process performance criteria}

The SMB performance is characterized by four process parameters: purity, recovery, solvent consumption and adsorbent productivity. For the case of a two-component separation in the SMB in which the less-retained species $A$ is recovered in the raffinate, and the more retained component $\mathrm{B}$ is recovered in the extract, process performance parameters are defined in Table 1 . When a racemic mixture is considered, $C_{F}^{A}=C_{F}^{B}$; then $\mathrm{SCX}=\mathrm{SCR} \cdot \mathrm{RCR} / \mathrm{RCX}$ and $\mathrm{PRX}=\mathrm{PRR} \cdot \mathrm{RCX} / \mathrm{RCR}$.

\section{SIMULATION RESULTS}

Model equations [eqs (10) and (11)] were numerically solved by using the PDECOL package (Madsen and Sincovec, 1979) based on the method of orthogonal collocation in finite elements (OCFE). There are four PDEs for each zone of the TMB. Partial differential equations were discretized in the axial direction using a number of finite elements NINT $=14$ with two interior collocation points $(\mathrm{NC}=2)$ in each element. The resulting system of ODEs $(\mathrm{NC} \times$ NINT $\times \mathrm{NPDE}=448$ ) was then integrated with the ODE solver GEARIB (Hindmarsh, 1976).

The effects of the rotation period, extract and feed flow rates, section length and number of intraparticle mass transfer units on the SMB performance were studied by simulation.

The adsorption equilibrium isotherm proposed by the Separex group (Nicoud, 1995) of bi-Langmuir type was used:

$$
q_{A}^{*}=\frac{2.69 C_{A}}{1+0.0336 C_{A}+0.0466 C_{B}}+\frac{0.10 C_{A}}{1+C_{A}+3 C_{B}}
$$

$$
q_{B}^{*}=\frac{3.73 C_{B}}{1+0.0336 C_{A}+0.0466 C_{B}}+\frac{0.30 C_{B}}{1+C_{A}+3 C_{B}} .
$$

In the above equations the liquid-phase concentrations of species $\mathrm{A}$ and $\mathrm{B}, c_{A}$ and $c_{B}$, respectively, are in

Table 1. SMB performance criteria

\begin{tabular}{lcc}
\hline Performance parameter & Extract & Raffinate \\
\hline Purity (\%) & $100 C_{X}^{B} /\left(C_{X}^{A}+C_{X}^{B}\right)$ & $100 C_{R}^{A} /\left(C_{R}^{A}+C_{R}^{B}\right)$ \\
Recovery (\%) & $100 C_{X}^{B} Q_{X} /\left(C_{F}^{A} Q_{F}\right)$ & $100 C_{R}^{A} Q_{R} /\left(C_{F}^{A} Q_{F}\right)$ \\
Solvent consumption $(1 / \mathrm{g})$ & $\left(Q_{E}+Q_{F}\right) /\left(C_{X}^{B} Q_{X}\right)$ & $\left(Q_{E}+Q_{F}\right) /\left(C_{R}^{A} Q_{R}\right)$ \\
Productivity (g/h/l of solid) & $C_{X}^{B} Q_{X} / V_{s}$ & $C_{R}^{A} Q_{R} / V_{s}$ \\
\hline
\end{tabular}


Table 2. Operating conditions and model parameters for the reference case

SMB operation conditions

Model parameters

Feed concentration:

Rotation period:

Recycling flow rate:

Eluent flow rate:

Extract flow rate:

Feed flow rate:

Raffinate flow rate:
$2.9 \mathrm{~g} / 1$ each
$180 \mathrm{~s}$
$35.38 \mathrm{ml} / \mathrm{min}$
$21.45 \mathrm{ml} / \mathrm{min}$

$17.98 \mathrm{ml} / \mathrm{min}$

$3.64 \mathrm{ml} / \mathrm{min}$

$7.11 \mathrm{ml} / \mathrm{min}$
Solid/fluid volumes, $(1-\varepsilon) / \varepsilon=1.5$

Number of mass transfer units, $\alpha=36.0$

Peclet number, $P e=2000$

Ratio between fluid and solid velocities

$\gamma_{\mathrm{I}}=6.65 ; \gamma_{\mathrm{II}}=4.23 ; \gamma_{\mathrm{III}}=4.72 ; \gamma_{\mathrm{IV}}=3.76$

Columns

Diameter: $2.6 \mathrm{~cm}$

Section length: $21.0 \mathrm{~cm}$

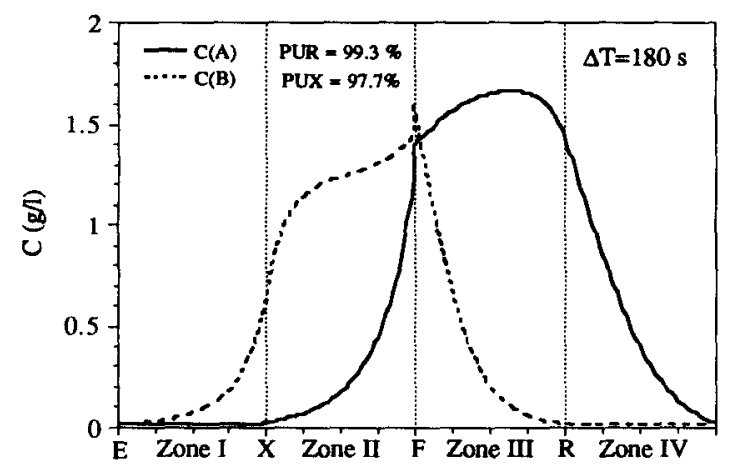

Fig. 4. Internal profiles for the reference case. $\mathrm{g} / \mathrm{l}$ of solution and the adsorbed-phase concentrations are expressed in $\mathrm{g} / 1$ of adsorbent.

A reference case relative to a eight-column configuration of the SMB, based on the values of operating variables and model parameters shown in Table 2 , was chosen and the influence of several operating variables was studied by simulation. The reference flow rates were provided by Nicoud (1995) and checked by using the equilibrium model for the SMB. The internal profiles for the reference case are shown in Fig. 4.

\section{Effect of the rotation period}

The influence of the rotation period on the system performance is shown in Fig. 5. It can be seen that high purities and recoveries can be obtained only in a narrow window of rotation periods. A similar
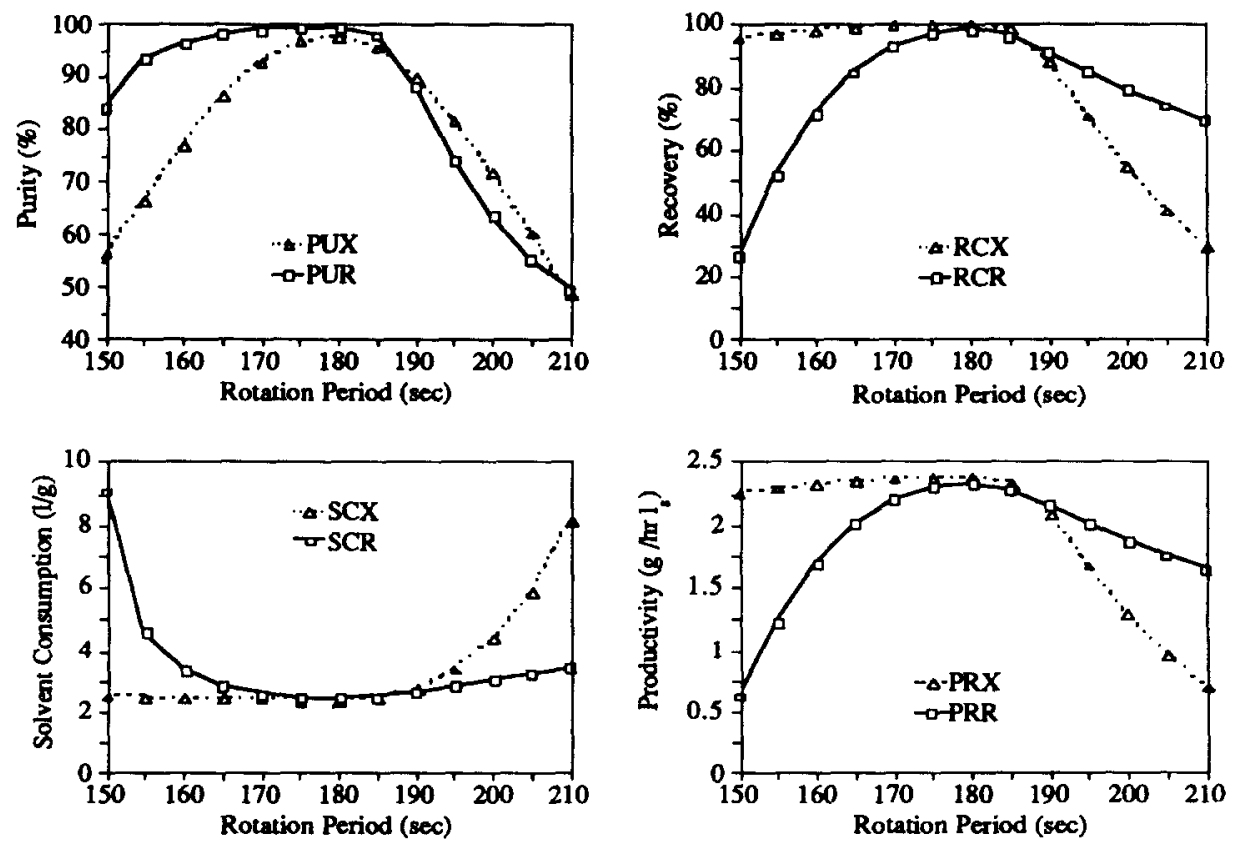

Fig. 5. Effect of the rotation period on the performance parameters. 
behavior could be obtained by changing the value of the liquid recycling flow rate instead of the rotation period; in fact, the rotation period or switching time is inversely proportional to the solid flow rate so the role of increasing the recycling liquid flow rate or decreasing the solid flow rate (increasing $\Delta T$ ) is similar with regard to the calculation of the net flux of a species.

Figure 6 shows recovery vs purity in the extract and raffinate for different rotation periods. It is clear that it is possible to obtain simultaneously high purities and recoveries in a simulated moving bed system, but the tuning has to be carefully done.

\section{Effect of the extract flow rate}

The effect of the extract flow rate $Q_{\mathrm{x}}$ on the SMB performance is shown in Fig. 7. The deviation of the extract flow rate from its optimum value drastically affects the performance of one or the other enantiomer, depending on which direction $Q_{\mathrm{x}}$ is changed.
In fact, increasing the extract flow rate will lead to a lower liquid flow rate $Q_{\mathrm{II}}$ and the constraint in zone II is eventually not obeyed; therefore, species A will have a net flux downwards and will contaminate the extract with decrease of purity in that stream. Again, simultaneous high purities for both enantiomers can only be obtained in a narrow window of values of the extract flow rate.

\section{Effect of the feed flow rate}

The effect of the feed flow rate on the SMB performance is shown in Fig. 8. Increasing the feed flow rate improves productivity and solvent consumption but reduces both purity and recovery. Increasing the feed flow rate means that $Q_{\text {III }}$ increases and the heavier species B will contaminate the raffinate stream; also the flow rate in zone IV increases and species $A$ eventually moves upwards which will contaminate the extract stream.
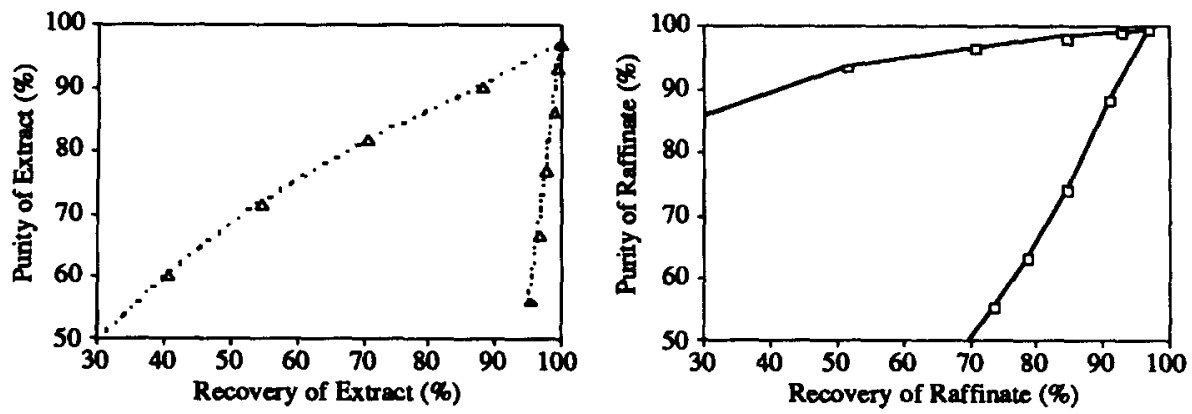

Fig. 6. Recovery vs purity for extract and raffinate.
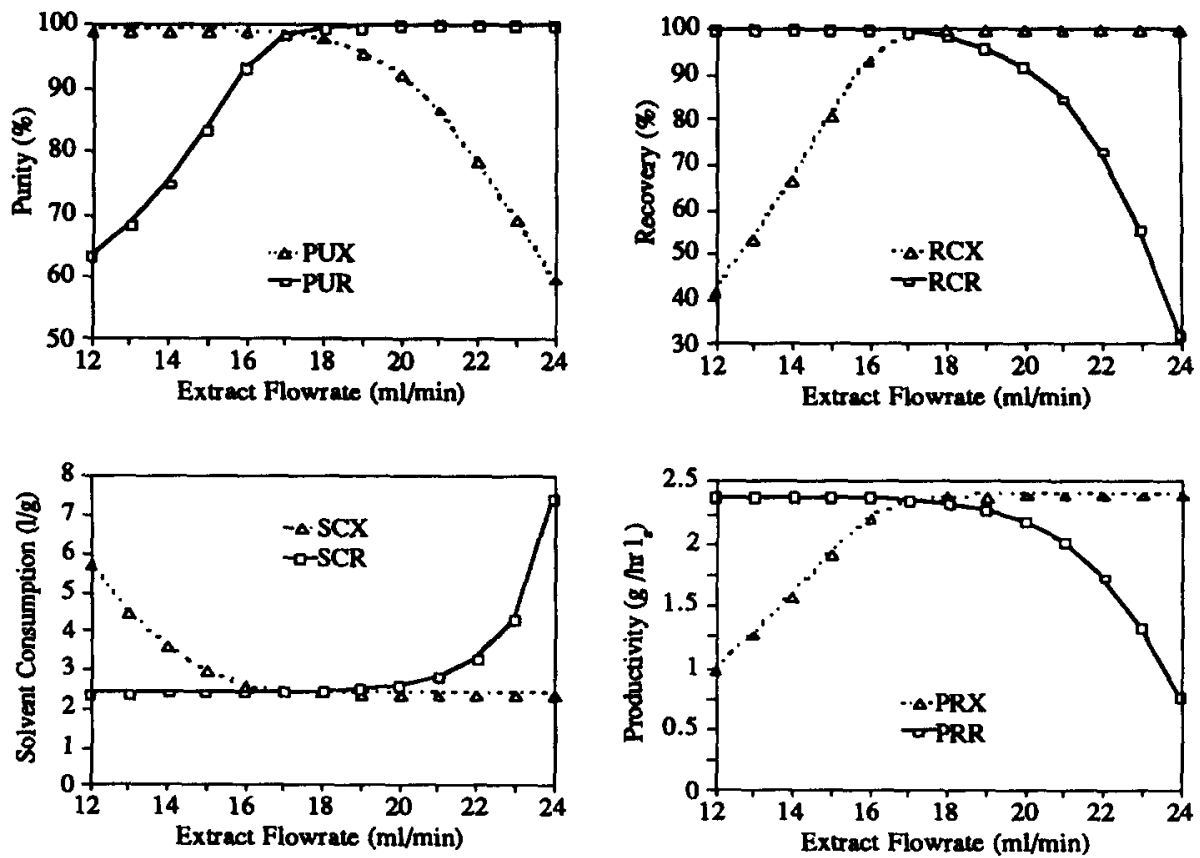

Fig. 7. Effect of the extract flow rate on the performance parameters. 

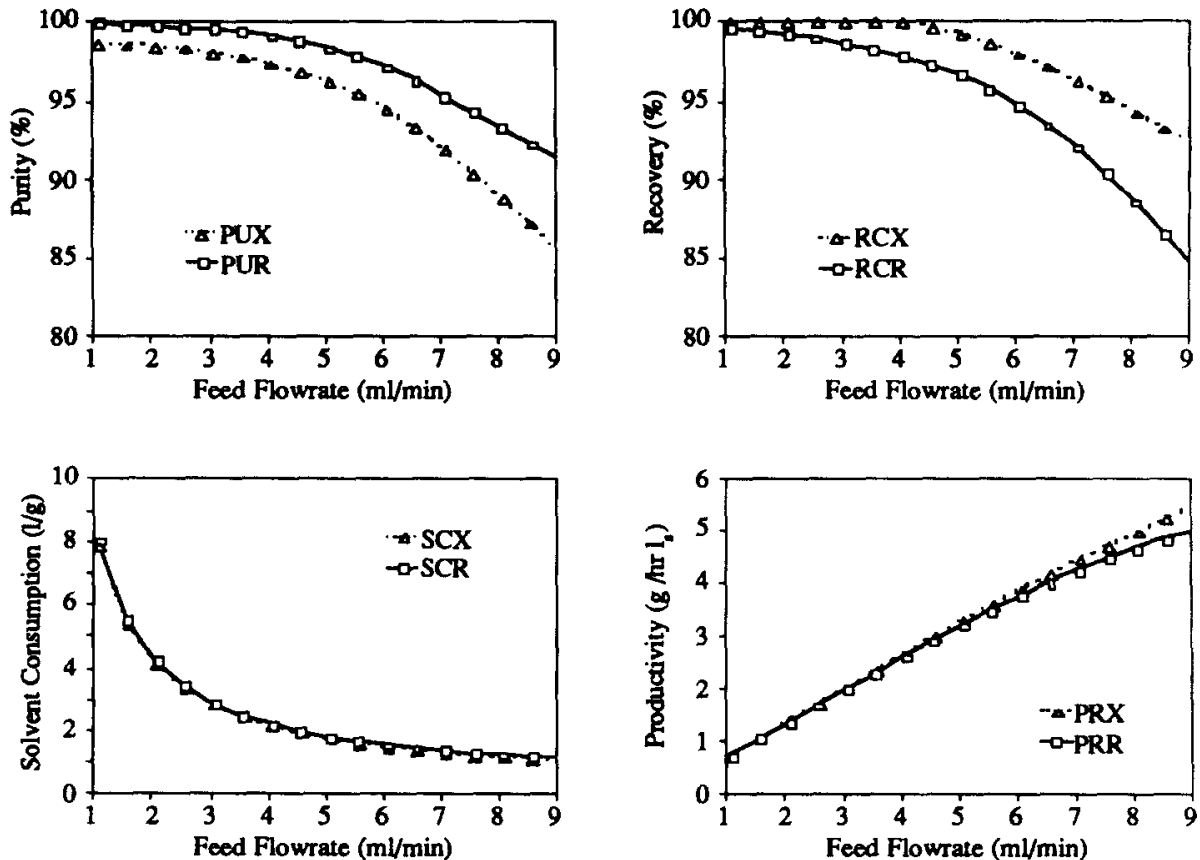

Fig. 8. Effect of the feed flow rate on the performance parameters.
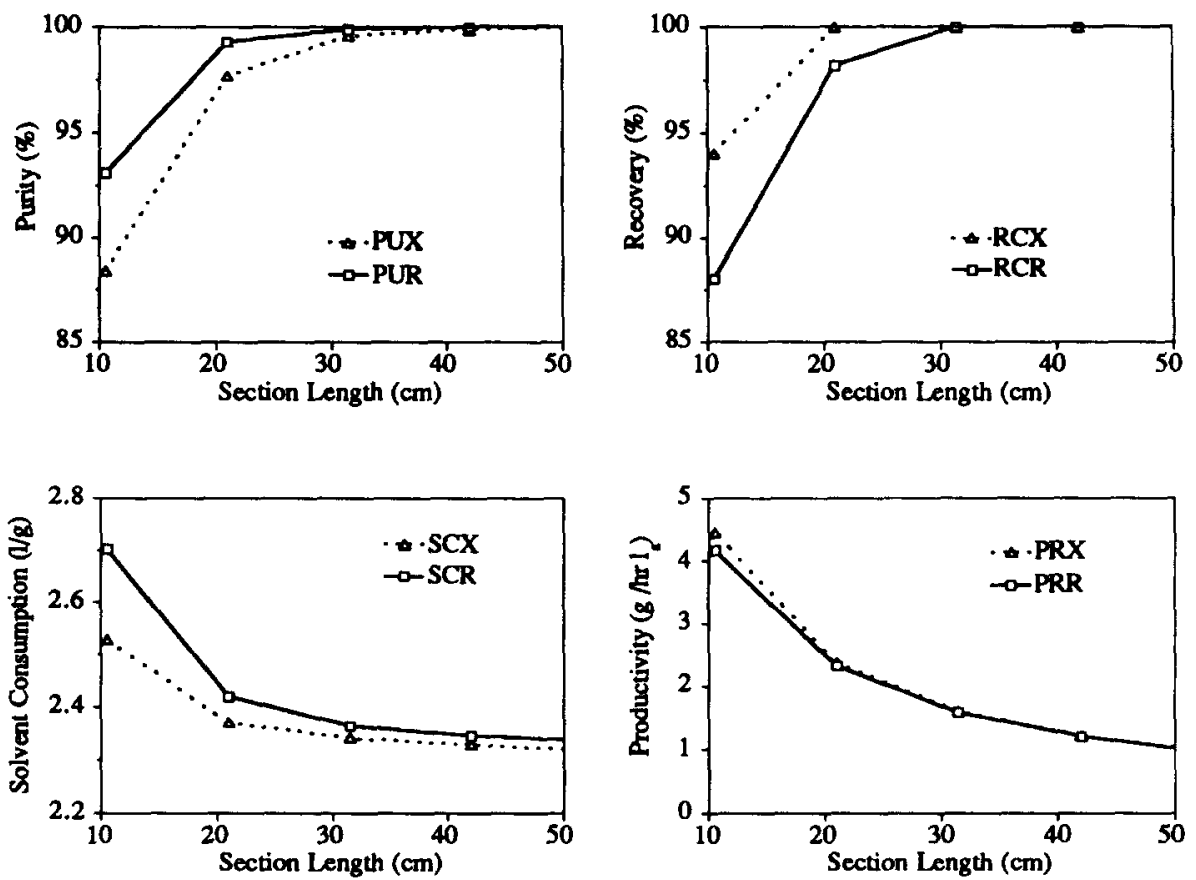

Fig. 9. Effect of the section length on the performance parameters

Effect of the section length

The effect of the section length is displayed in Fig. 9. With the mass transfer coefficient used $\left(k=0.1 \mathrm{~s}^{-1}\right)$, no significant improvement in the system performance is observed for section length greater than $31.5 \mathrm{~cm}$, i.e. 3 columns per section in the SMB configuration Obviously, the optimum configuration does not require an equal number of columns in each section.
These results also show that it is possible to obtain an almost complete separation using an 8- or 12column configuration (two or three columns per section) in the SMB pilot with $10.5 \mathrm{~cm}$ long columns.

Effect of the number of intraparticle mass transfer units

The effect of the intraparticle mass transfer rate $k$ or the corresponding dimensionless number $\alpha$ on the 

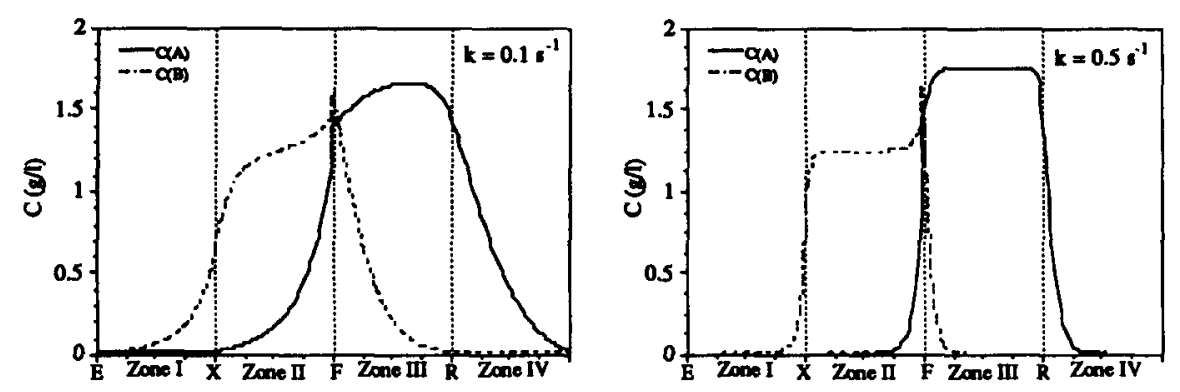

Fig. 10. Effect of the intraparticle mass transfer rate on the cyclic steady-state SMB internal profiles
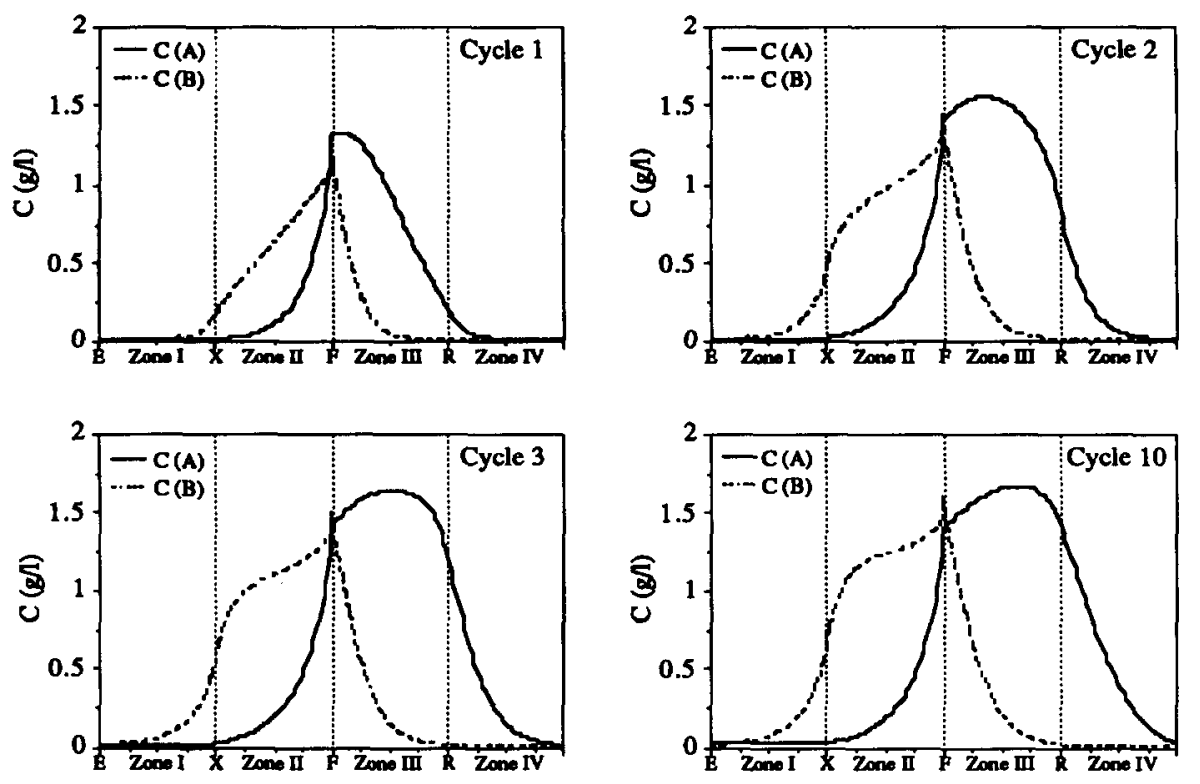

Fig. 11. Transient SMB internal profiles for the reference case.

cyclic steady-state internal profiles of the SMB is shown in Fig. 10 for $\alpha=36$ and $\alpha=180$ (or $k=$ $0.1 \mathrm{~s}^{-1}$ and $k=0.5 \mathrm{~s}^{-1}$ ). The mass transfer coefficient depends only on the intraparticle diffusivity of species and particle size. Therefore, increasing $\alpha$ (or $k$ ) by decreasing the particle size improves the performance of the SMB, provided the constraint of acceptable pressure drop is met. Some applications in the area of protein processing will eventually use large-pore permeable particles in which intraparticle mass transport by convective flow is important, leading to an enhancement of the mass transfer rate. The above model can still be used in that case if the mass transfer coefficient $k$ is replaced by an 'augmented' mass transfer coefficient $\tilde{k}$ (Leitão and Rodrigues, 1995).

Evolution of the internal profiles for transient operation of the $T M B$

The evolution of the transient internal profiles for the TMB operation was also evaluated in the reference case and is shown in Fig. 11 for cycles 1, 2, 3 and 10 (cyclic steady state). The front of the less-adsorbed species $\mathrm{A}$ is progressing in zone III leading to a A-rich raffinate stream. A limited number of cycles is sufficient to reach the final cyclic steady state.

Figure 12 shows the transient SMB performance in terms of purity and recovery of the extract and raffinate as a function of the cycle number.

\section{OPERATION OF THE SIMULATED MOVING BED}

\section{$S M B$ pilot plant}

The SMB pilot unit used in this work is the LICOSEP 12-26 (SEPAREX, Champigneulles, France) shown in Fig. 13. It is a continuous chromatographic system constituted by 12 columns connected in series.

The columns are Superformance 300-26 (Merck, Darmstadt, Germany) with $26 \mathrm{~mm}$ internal diameter and adjustable length $(5-20 \mathrm{~cm})$. They have a jacket which allows operation of the SMB up to $60^{\circ} \mathrm{C}$. Each column is connected with four lines (eluent, feed, extract and raffinate lines) and 48 two-way highpressure pneumatic valves (TOP Industrie, France) allow the connection of the inlet--outlet lines of the columns. 

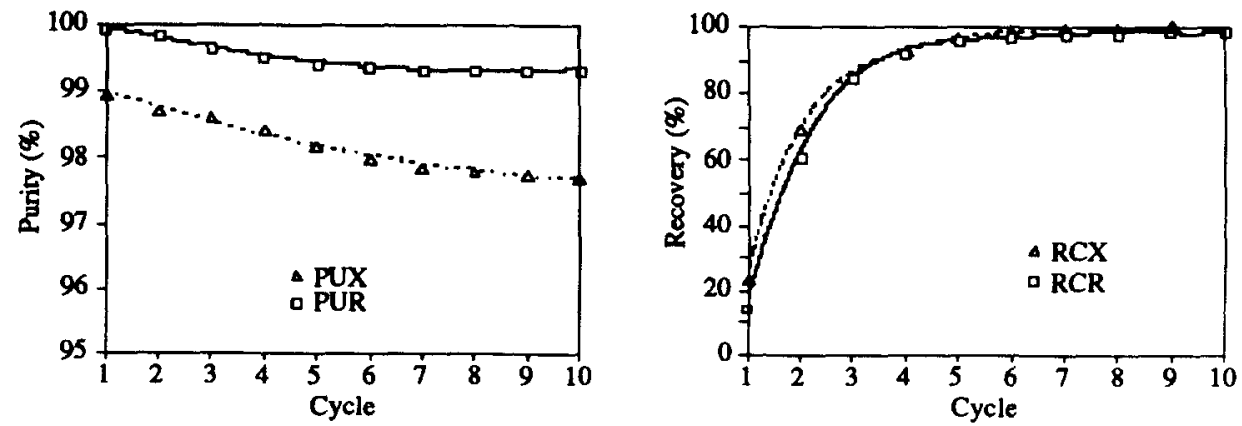

Fig. 12. Transient SMB performance: purity and recovery of extract and raffinate vs cycle number

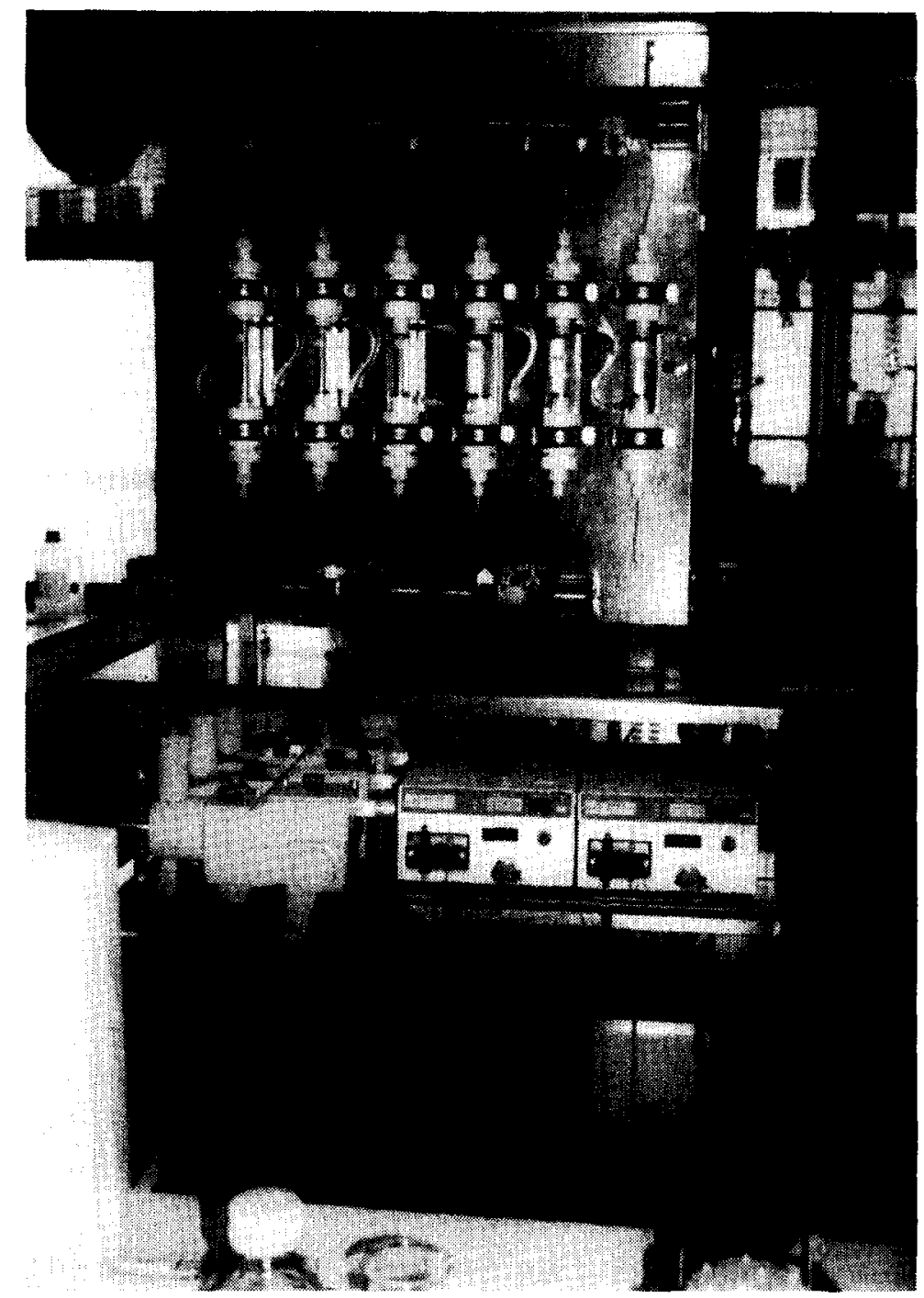

Fig. 13. Licosep 12-26 pilot plant.

A three-head membrane pump (Milroyal, Pont St Pierre, France) is used for the recycle flow. The other flows (eluent, feed, extract and raffinate) are controlled by four pumps Merck-Hitachi (Darmstadt, Germany), connected to the computer via RS 232.
The system temperature is measured and controlled through a thermostatic bath. The SMB unit can stand pressures up to 60 bar.

The SMB pilot is controlled by a central system using the LICOSEP control software. 


\section{$S M B$ operation}

The operation of the SMB pilot for the bi-naphthol enantiomers (molecular weight $M_{w}=286.3$ ) purification was carried out using a eight-column configuration. Columns are made of 3,5-dinitrobenzoyl phenylglycine bonded to silica gel (Merck, Darmstadt, Germany). Each column is $10.5 \mathrm{~cm}$ long. Silica particles have diameter in the range $25-40 \mu \mathrm{m}$. The eluent used was a $72 / 28(\mathrm{v} / \mathrm{v})$ heptane/isopropanol mixture. Operation temperature was fixed at $25^{\circ} \mathrm{C}$.

The samples collected were analyzed in a HPLC system using a $250 \mathrm{~mm}$ (length) $\times 4 \mathrm{~mm}$ (diameter) column filled with $5 \mu \mathrm{m}$ poly-N-acryloyl-(S)-phenylalanine diethylamide as stationary phase. The eluent was the same mixture of heptane/isopropanol and outlet concentration was followed by UV detection at $254 \mathrm{~nm}$.

Two runs were carried out for different values of extract/raffinate flow rates and the optimum performance was achieved by choosing the best rotation period. Table 3 presents the experimental conditions for the SMB pilot.

The internal profiles were measured using the 6port valve of the Licosep SMB pilot to withdraw samples from the system. The samples were collected at each half-time period and after 40 full cycles of continuous operation. The experimental performance parameters were determined by analysis of the extract and raffinate samples collected during the whole cycle 40 (cyclic steady state).

The performance parameters for both runs are shown in Table 4. For a rotation period of $172 \mathrm{~s}$, purities as high as $94.5 \%$ in the extract and $98.9 \%$ in the raffinate can be obtained with good recoveries.

Figure 14 shows the SMB experimental internal profiles at cyclic steady state. Simulated results are also displayed using $k=0.1 \mathrm{~s}^{-1}$ (symbols are experimental results, lines for model simulation). The agreement between model and experimental results is

Table 3. Experimental conditions for the bi-naphthol system

\begin{tabular}{lcc}
\hline & Run 1 & Run 2 \\
\hline Column length, cm & 10.5 & \\
Number of columns & 8 & \\
Feed concentration, g/ each & 2.9 & \\
Recycling flow rate, ml/min & 35.38 & \\
Eluent flow rate, $\mathrm{ml} / \mathrm{min}$ & 21.45 & \\
Extract flow rate, $\mathrm{ml} / \mathrm{min}$ & 17.98 & 16.00 \\
Feed flow rate, $\mathrm{ml} / \mathrm{min}$ & 3.64 & \\
Raffinate flow rate, $\mathrm{ml} / \mathrm{min}$ & 7.11 & 9.09 \\
\hline
\end{tabular}

reasonable except for the concentration of the moreretained component $B$ in the column before the feed inlet. This discrepancy may be due to the fact that the sample is collected at the half-time period; the composition at that time can be different from the average composition in the whole rotation period. It can also be related with an inaccurate description of the binary adsorption equilibrium.

\section{CONCLUSIONS}

The separation of bi-naphthol enantiomers was carried out in a SMB pilot unit LICOSEP 12-26. Operating conditions for successful operation leading to high extract and raffinate purities as well as high recoveries were based on process simulation.

A model for predicting the cyclic steady-state behavior of the simulated moving bed (SMB) is developed using the correspondent true moving bed (TMB) approach. The model also enables the prediction of the TMB transient behavior. This SMB package is an important learning and training tool used to
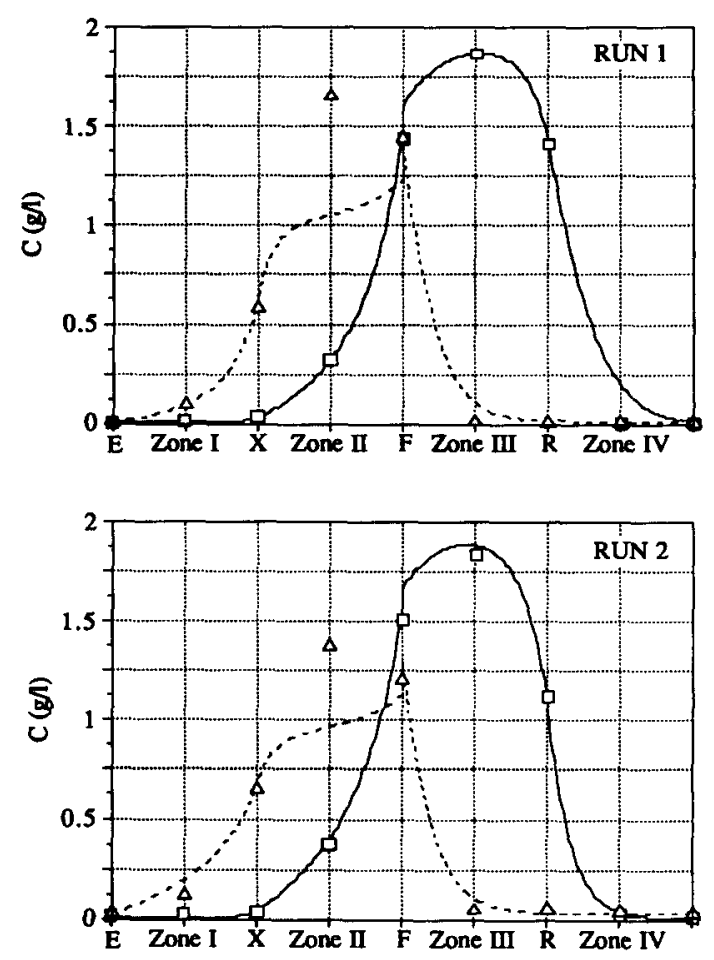

Fig. 14. Operation of SMB pilot unit: comparison between experimental and simulated results for runs 1 and 2 .

Table 4. Experimental performance parameters for the two runs

\begin{tabular}{llllllllll}
\hline Run & $\begin{array}{l}\Delta T \\
(\mathrm{~s})\end{array}$ & $\begin{array}{l}\text { PUX } \\
(\%)\end{array}$ & $\begin{array}{l}\text { PUR } \\
(\%)\end{array}$ & $\begin{array}{l}\text { RCX } \\
(\%)\end{array}$ & $\begin{array}{l}\text { RCR } \\
(\%)\end{array}$ & $\begin{array}{l}\text { SCX } \\
(1 / \mathrm{g})\end{array}$ & $\begin{array}{l}\text { SCR } \\
(1 / \mathrm{g})\end{array}$ & $\begin{array}{l}\text { PRX } \\
\left(\mathrm{g} / \mathrm{h} / \mathbf{l}_{\mathrm{s}}\right)\end{array}$ & $\begin{array}{c}\text { PRR } \\
\left(\mathrm{g} / \mathrm{h} / \mathbf{l}_{\mathrm{s}}\right)\end{array}$ \\
\hline 1 & 172 & 94.5 & 98.9 & 99.1 & 94.1 & 2.37 & 2.50 & 2.37 & 2.25 \\
2 & 165 & 93.0 & 96.2 & 97.3 & 91.6 & 2.44 & 2.59 & 2.31 & 2.17 \\
\hline
\end{tabular}


predict the effect of operating variables on the process performance, and so the choice of the best conditions for the SMB operation.

The package was also used to predict the steadystate internal profiles for the SMB operation in good agreement with experimental results.

\section{Acknowledgements}

Financial support from the European Community under the BRITE-EURAM Programme (Contract no. BRE2CT92-0337) is gratefully acknowledged. Thanks are also due to R. M. Nicoud and J. Blehaut (Separex) and J. Kinkel (Merck) for helpful discussions and preparation of the chiral packing.

\section{NOTATION}

$c_{i j}$

fluid-phase concentration of component $i$ in section $j, \mathrm{~kg} / \mathrm{m}^{3}$

$D_{L,} \quad$ axial dispersion coefficient in the $j \mathrm{sec}$ tion, $\mathrm{m}^{2} / \mathrm{s}$

$k$ mass transfer coefficient, $\mathrm{s}^{-1}$

$L_{c} \quad$ column length, $\mathrm{m}$

$L_{j} \quad$ section length, $m$

$\dot{M} \quad$ solid flow rate, $\mathrm{m}^{3} / \mathrm{s}$

$N_{s} \quad$ number of columns per section in the SMB system

$P e_{j} \quad$ Peclet number for section $j\left(=v_{j} L_{j} / D_{L_{j}}\right)$

PRR productivity for the raffinate, $\mathrm{kg}$ of product $\mathrm{s} / \mathrm{m}^{3}$ adsorbent

PRX productivity for the extract, $\mathrm{kg}$ of product $/ \mathrm{s} / \mathrm{m}^{3}$ adsorbent

PUR purity of the raffinate, dimensionless

PUX purity of the extract, dimensionless

$q_{i j} \quad$ average adsorbed-phase concentration of component $i$ in section $j, \mathrm{~kg} / \mathrm{m}^{3}$ adsorbent

$q_{i j}^{*} \quad$ adsorbed concentration of component $i$ in section $j$ in equilibrium with $C_{i j}, \mathrm{~kg} / \mathrm{m}^{3}$ adsorbent

$Q \quad$ flow rate, $\mathrm{m}^{3} / \mathrm{s}$

RCR recovery of $A$ in the raffinate, dimensionless

RCX recovery of $B$ in the extract, dimensionless

SCR solvent consumption for the raffinate, $\mathrm{m}^{3}$ solvent $/ \mathrm{kg}$ of product

SCX solvent consumption for the extract, $\mathrm{m}^{3}$ solvent $/ \mathrm{kg}$ of product

$t \quad$ time. $s$

$\Delta T \quad$ rotation period, $\mathrm{s}$

$u_{s} \quad$ solid velocity, $\mathrm{m} / \mathrm{s}$

$V_{s} \quad$ volume of the solid phase, $\mathrm{m}^{3}$

$v_{j} \quad$ interstitial fluid velocity in the $j$ section, $\mathrm{m} / \mathrm{s}$

$x$ dimensionless axial coordinate $\left(=z / L_{j}\right)$

$z \quad$ axial coordinate, $\mathrm{m}$

Greek letters

$\alpha_{j}$

number of mass transfer units $\left(=k \tau_{s}\right)$, dimensionless

$\gamma_{j} \quad$ ratio between fluid and solid velocities $\left(=v_{j} / u_{s}\right)$, dimensionless

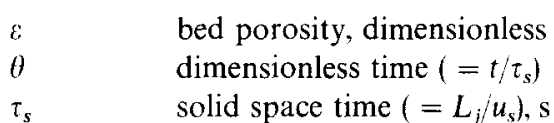

Subscripts and superscripts

A less-retained component

$B \quad$ more-retained component

E eluent

$F \quad$ feed

$R \quad$ raffinate

$R F$ recycling flow rate

$X \quad$ extract

\section{REFERENCES}

Baciocchi, R., Mazzotti, M., Storti, G., and Morbidelli, M., (1995) $C_{5}$ separation in a vapor phase simulated moving bed unit. In Proceedings of the 5th International Conference on Fundamentals of Adsorption, U.S.A.

Bailly, M. and Nicoud, R. M. (1993) The simulated moving bed: a powerful process for purification. In Biotechnology of Blood Proteins, eds C. Rivat and J. Stoltz, Vol. 227, p. 237. Colloque INSERM/John Libbey Eurotext Ltd.

Bailly, M., Tondeur, D. and Grevillot, G. (1984) Du lit mobile simulé à la chromatographie à double sens. Nouveaux modes operatoires pour la chromatographie productive, Inform. Chim. 255, 237.

Balannec, B. and Hotier, G. (1993) From batch elution to simulated countercurrent chromatography. In Preparative and Production Scale Chromatography, eds G. Ganetsos and P. E. Barker. eds., Marcel Dekker, New York, U.S.A.

Barker, P., Knoechelmann, A. and Ganetsos, G. (1990) Simulated counter-current moving column chromatography used in the continuous separation of carbohydrate mixtures. Chromatographia 29, 161.

Broughton, D. B. (1961) U.S. Patent 2,985,589

Broughton, D. B. (1968) Molex: case history of a process. Chem. Engng Prog. 64, 60.

Broughton, D. B. (1970) The parex process for recovering paraxylene. Chem. Engng Prog. 66, 70.

Broughton. D. B. (1984) Production-scale adsorptive separations of liquid mixtures by simulated moving bed technology. Sep. Sci. Technol. 19, 723.

Ching, C. B. and Ruthven, D. M. (1985) An experimental study of a simulated counter-current adsorption system - -I. Isothermal steady state operation. Chem. Engng Sci. 40, 877.

Ching, C. B., Ruthven, D. M. and Hidajat, K. (1985) Experimental study of a simulated counter-current adsorption system--III. Sorbex operation. Chem. Engng Sci. 40, 1411.

Ching, C. B., Ho, C., Hidajat, K. and Ruthven, D. M. (1987) Experimental study of a simulated countercurrent adsorption system-V. Comparison of resin and zeolite absorbents for fructose-glucose separation at high concentration. Chem. Engng $S_{c i}$. 42, 2547.

Ching, C. B., Ho, C. and Ruthven, D. M. (1988) Experimental study of a simulated counter-current adsorption system--VI. Non-linear systems. Chem. Engng Sci. 43, 703. 
Ching, C. B., Chu, K. H., Hidajat, K. and Uddin, M. S. (1992) Comparative study of flow schemes for a simulated countercurrent adsorption separation process. A.I.Ch.E. J. 38, 1744.

Ching, C. B., Lim, B. G., Lee, E. J. D. and Ng, S. C. (1993) Preparative resolution of praziquantel enantiomers by simulated counter-current chromatography. J. Chromatogr. 634, 215.

Chu, K. H. and Hashim, M. A. (1995) Simulated countercurrent adsorption processes: a comparison of modelling strategies. Chem. Engng $J$. 56, 59.

Dandekar, H. W., Chandhok, A. K. and Priegnitz, J. W. (1995) Modeling and simulation of SMB technology for pharmaceutical and fine chemical applications. In Proceedings of the 5th International Conference on Fundamentals of Adsorption, U.S.A.

de Rosset, A. J., Neuzil, R. W. and Broughton, D. B. (1981) Industrial applications of preparative chromatography. In NATO ASI Percolation Processes, Theory and Applications, eds A. E. Rodrigues and D. Tondeur, Sijthoff \& Noordhoff International Publishers, The Netherlands.

de Rosset, A. J., Neuzil, R. W., Tajbl, D. and Braband, J. (1980) Separation of ethylbenzene from mixed xylenes by continuous adsorptive processing. Sep. Sci. Technol. 15, 637-653.

Fuchs G., Nicoud, R. M. and Bailly, M. (1992) Optical isomers purification with the simulated moving bed technology: experimental and theoretical approaches. In Proceedings of the 9th International Symposium on Preparative and Industrial Chromatography, ed. M. Perrut. Soc. Française de Chimie, Nancy, France.

Gattuso, M. J., McCulloch, B. and Priegnitz, J. W. (1994) UOP sorbex simulated moving bed technology. A cost effective route to chiral products. In Chiral Europe.

Gattuso, M. J., McCulloch, B., House, D. W. and Baumann, W. M. (1995) UOP simulated moving bed technology-The preparation of single enantiomer drugs. In Chiral U.S.A.

Gottschall, K., Kay, M. and Reusch, J. (1994) Simulated moving bed chromatography. PREP'94, Baden-Baden, Germany.

Hashimoto, K., Adachi, S., Noujima, H. and Maruyama, H. (1983) Models for the separation of glucose/fructose mixture using a simulated movingbed adsorber. J. Chem. Engng Japan 16, 400.

Hashimoto, K., Yamada, M., Shirai, Y. and Adachi, S. (1987) Continuous separation of glucose-salts mixture with nonlinear and linear adsorption isotherms by using a simulated moving-bed adsorber. $J$. Chem. Engng Japan 20, 405.

Hashimoto, K., Yamada, M., Adachi, S. and Shirai, Y. (1989) A simulated moving-bed adsorber with three zones for continuous separation of $\mathrm{L}$-phenylalanine and $\mathrm{NaCl}$. J. Chem. Engng Japan 22, 432.

Hassan, M. M., Rahman, A. K. M. S. and Loughlin, K. F. (1995) Modelling of simulated moving bed adsorption system: a more precise approach. Sep. Technol. 5, 77.

Hidajat, K., Ching, C. B. and Ruthven, D. M. (1986a) Simulated counter-current adsorption processes: a theoretical analysis of the effect of subdividing the adsorbent bed. Chem. Engng Sci. 41, 2953.
Hidajat, K., Ching, C. B. and Ruthven, D. M. (1986b) Numerical simulation of a semi-continuous countercurrent adsorption unit for fructose-glucose separation. Chem. Engng J. 33, B55.

Hindmarsh, A. C. (1976) GEAR-ordinary differential equations systems solver. UCID-30001 Rev. 3 Report, Lawrence Livermore Laboratory, Livermore.

Hotier, G. and Balannec, B. (1991) Chromatographie a contre-courant simulé: développements et perspectives. Rev. Institut Français P'́trole 46, 803-820.

Humphrey, J. L., (1995) Separation processes: playing a critical role, Chem. Engng Prog. 91 (10) 31-41.

Johnson, J. A. (1989) Sorbex: continuing innovation in liquid phase adsorption. In NATO ASI Adsorption: Science and Technology, eds. A. E. Rodrigues et al. Kluwer Academic Publishers, Dordrecht, the Netherlands.

Johnson, J. A. and Kabza, R. G. (1993) Sorbex: industrial-scale adsorptive separation. In Preparative and Production Scale Chromatography, eds G. Ganetsos and P. E. Barker. Marcel Dekker, New York, U.S.A.

Keller II, G. E. (1995) Adsorption: building upon a solid foundation. Chem. Engng Prog. 91 (10) 56-67.

Kishihara, S., Horikawa, H., Tamaki, H., Fujii, S., Nakajima, Y. and Nishio, K. (1989) Continuous chromatographic separation of palatinose and trehalulose using a simulated moving-bed adsorber. J. Chem. Engng Japan 22, 434.

Knaebel, K. S. (1995). For your next separation consider adsorption. Chem. Engng 102 (11) 92-102.

Kubota, K., Hata, C. and Hayashi, S. (1989) A study of a simulated moving bed adsorber based on the axial dispersion model. Can. J. Chem. Engng 67, 1025.

Leitão, A. and Rodrigues, A. (1995) Adsorptive processes using large-pore materials: analysis of a criterion for equivalence of diffusion-convection, "apparent" diffusion and "extended" linear driving force models. Chem. Engng J. 60, 81-88.

Madsen, N. and Sincovec, R. (1979) PDECOL: general collocation software for partial differential equations. ACM Trans. Math. Soft. 5326.

Mazzotti, M., Storti, G. and Morbidelli, M. (1994) Robust design of countercurrent adsorption separation processes: 2. Multicomponent systems. A.I.Ch.E. J. 40, 1825.

Negawa, M. and Shoji, F. (1992) Optical resolution by simulated moving-bed adsorption technology. $J$. Chromatagr. 590, 113.

Nicoud, R. M., (1992) the simulated moving bed: a powerful chromatographic process. $L C-G C$ Int. 5 , 43.

Nicoud, R. M., (1995) Personal communication.

Nicoud, R. M., Fuchs, G., Kusters, E., Antia, F., Reuille, R. and Schmid, E. (1992) Preparative scale enantioseparation of a chiral epoxide - a comparison of liquid chromatography and simulated moving-bed adsorption technology. In Proceedings of the 3rd International Symposium on Chiral Discrimination, Tubigen.

Nicoud, R. M., Fuchs, G., Adam, P., Bailly, M., Kusters, E., Antia, F., Reuille, R. and Schmid, E. (1993) Preparative scale enantioseparation of a chiral epoxide: a comparison of liquid chromatography and simulated moving-bed adsorption technology. Chirality 5, 267-271. 
Nicoud, R. M., (1993) Simulated Moving Bed: Basics and Applications. European Meeting, Nancy, France.

Rahman, A. K. M. S., Hassan, M. M. and Loughlin, K. F. (1994) Unsteady state simulation of sorbex system with nonlinear adsorption isotherms. Sep. Technol. 4, 27.

Rodrigues, A. E., Lu, Z. P, Loureiro, J. M. and Pais, L. S. (1995a) Separation of enantiomers of $1 \mathrm{a}, 2,7,7 \mathrm{a}-$ tetrahydro-3-methoxynaphtha(2,3b)-oxirane by liquid chromatography: laboratory-scale elution chromatography and modelling of simulated moving bed. J. Chromatagr. 702, 223.

Rodrigues, A. E., Loureiro, J. M., Lu, Z. P. and Pais, L. S. (1985b) Modeling and operation of a simulated moving bed for the separation of optical isomers. In Proceedings of the 5th International Conference on Fundamentals of Adsorption, USA.

Ruthven, D. M. and Ching, C. B. (1985) Countercurrent and simulated counter-current adsorption separation processes. Chem. Engng Sci. 44, 1011.

Sheldon, R. A. (1993) Chirotechnology: Industrial Synthesis of Optically Active Compounds. Marcel Dekker, New York, U.S.A.

Stinton, S. C. (1995) Chiral drugs, C\&EN, 44-74.
Storti, G., Masi, M., Paludeto, R., Morbidelli, M. and Carrà, S. (1988) Adsorption separation processes: countercurrent and simulated countercurrent operations. Comput. Chem. Engng 12, 475.

Storti, G., Masi, M., Carrà, S. and Morbidelli, M. (1989a) Optimal design of multicomponent countercurrent adsorption separation processes involving nonlinear equilibria. Chem. Engng $S_{c}$ 't. 44. 1329.

Storti, G., Masi, M. and Morbidelli, M. (1989b) On countercurrent adsorption separation processes. In NATO ASI Adsorption: Science and Technology, eds A. E. Rodrigues et al. Kluwer Academic Publishers, Dordrecht. The Netherlands.

Storti, G., Mazzotti, M., Furlan, L. T. and Morbidelli, M. (1992) Analysis of a six port simulated moving bed separation unit. In Proceedings of the Fourth International Conference on Fundamentals of Adsorption, ed. Suzuki, M. Kodansha, Tokyo.

Storti, G., Mazzotti. M., Morbidelli, M. and Carrà, S. (1993) Robust design of binary countercurrent adsorption separation processes. A.I.Ch.E. J. 39. 471 . 